\title{
Quarantining, Social Distancing and Face Mask Wearing of People during COVID-19 Pandemic: Which are Feasible?
}

\author{
Shyamapada Mandal ${ }^{1 *}$ and Manisha Mandal $^{2}$ \\ ${ }^{1}$ Laboratory of Microbiology and Experimental Medicine, Department of Zoology, \\ University of Gour Banga, Malda, India \\ ${ }^{2}$ Department of Physiology, MGM Medical College, Kishanganj, India \\ *Corresponding Author: Shyamapada Mandal, Laboratory of Microbiology and \\ Experimental Medicine, Department of Zoology, University of Gour Banga, Malda, \\ India.
}

The COVID-19 (coronavirus disease 2019), which is a rapidly spreading respiratory illness, is caused with the infection of SARS-CoV-2 (severe acute respiratory syndrome coronavirus 2) [1]. Since the first emergence of SARS-CoV-2, the virus that causes COVID-19 outbreak in Wuhan city (Hubei province, China) in December 2019, globally 2,164,111 confirmed cases have been registered, and 146,198 have been deceased, as of April 19, 2020, till to submit this paper [2]. The trend of infection with emergence of new cases is accelerating day-by-day, around the world, in 211 countries, areas or, territories from all six regions of the WHO (World Health Organization) [2]. Currently, there has been a report on control measures with high grade physical distancing (such as lockdowns) as explained by Kissler., et al. [3], in response to the prevention of the highly contagious disease, COVID-19, which has been declared a pandemic by the WHO, on March 11, 2020 [2].

The rapid upsurge of global COVID-19 pandemic is, now, making the situation so overwhelming that the countries leaders are inevitably taking unprecedented and stringent measures to the containment of the disease, because of lack of pharmaceutical treatments as well as vaccines [3,4]. Such measures included: (a) quarantine (defined as separation and restriction of movement of persons who have been exposed to an infectious disease to see if they become sick), (b) isolation (which is a medical provision for the separation of persons who are known to be infected with disease from people who are not sick) and (c) physical/social distancing (a kind of infection control measure wherein people require to stay in safe distance, at least 6 feet, among one another in order to block transmission), also called spatial distancing. This is in line with what the WHO implored emphatically for the 'containment' measures together with social/physical distancing, rapid clinical care and global solidarity development, since the COVID-19 (that was unequivocally unknown until December 2019 that China got first with a possible single zoonotic spillover in Wuhan, Hubei province) has disrupted the global public health systems [1,2]. The CDC has advanced safety and preventive measures on warding off the infection with SARS-CoV-2 that spread basically through respiratory droplets by coughing and sneezing, via exhalation and close contact of COVID-19 patients (symptomatic cases) or people who acquired viral contraction (asymptomatic cases) [5]. Currently, in view of the containment of COVID-19, it has been explained that before January 30, 2020 (that included first 7-day of China's lockdowns), China had a reproductive number (which is defined as the average number of new COVID-19 cases resulted by each of the infected persons, and is the determinative for the SARS-CoV-2 transmissibility) $\mathrm{R}>1$, while after January 30 (China's post lockdown periods), the reproductive number reduced to $<1$, indicating the effectiveness of non-pharmaceutical strategies (quarantine as well as lockdown measures) in preventing the spread of COVID-19 [6].

Moreover, since asymptomatic transmission of the virus, SARSCoV-2, occurs [7], prevention of COVID-19 in the local as well as global community (due to person-to-person transmission from undetected asymptomatic cases) might be possible if everyone (excluding children of $<2$ years): susceptible, old and comorbid people, wear face masks properly (provided that there is no shortage in the stockpiles), that, otherwise, are restricted to clinical as well as hospital settings by the front-line health-care staff [8]. Notably, use of cloth face masks in public is currently permitted as per the recommendation of the CDC [9]. This (face mask wearing) is in consideration with the fact that long term application of containment measures, and extensive lockdowns (in order to meet the humanitarian crisis) might not be practicable, and mask wearing in public is not the substitute measure of physical distancing, anti-SARS-Cov-2 antivirals as well as prophylactic measures and vaccines in order to combat COVID-19 are of high global demand, which, but, are not in hand. So that other approaches to the nonpharmaceutical COVID-19 infection control measures (testing and case isolation and contact tracing and quarantine), combined with physical distancing as well as face mask wearing [10], must not be overlooked, since everyone might possibly be contracted with the infection of the virus, SARS-CoV-2. Therefore, countries early lockdowns to maintain massive physical/social distancing (with hygienic respiratory etiquette and handwashing) might be effective, alongside the solidarity establishment from local, national through global levels, to fighting the virus, SARS-CoV-2 that compelled to 'stuck-at-home' situation. Finally, we have to learn how to survive the virus, SARS-CoV-2. 


\section{Bibliography}

1. Zhou P., et al. "A pneumonia outbreak associated with a new coronavirus of probable bat origin". Nature 579.7798 (2020): 270-273.

2. WHO. Coronavirus disease (COVID-19) pandemic. WHO (2020).

3. Kissler SM., et al. "Projecting the transmission dynamics of SARS-CoV-2 through the post pandemic period". Science (2020): eabb5793.

4. Nature News. "Coronavirus latest". Nature (2020).

5. CDC. Coronavirus disease (COVID-19). CDC (2020).

6. Zhao $\mathrm{S}$ and Chen H. "Modeling the epidemic dynamics and control of COVID-19 outbreak in China". Quantitative Biology 8 (2020): 11-19.

7. Bai Y., et al. "Presumed asymptomatic carrier transmission of COVID-19". Journal of the American Medical Association (2020).

8. Feng S., et al. "Rational use of face masks in the COVID-19 pandemic". Lancet Respiratory Medicine (2020).

9. CDC. "Coronavirus disease 2019 (COVID-19): recommendation regarding the use of cloth face coverings, especially in areas of significant community-based transmission". CDC (2020).

10. Cheng KK., et al. "Wearing face masks in the community during the COVID-19 pandemic: altruism and solidarity". Lancet (2020).

\section{Assets from publication with us}

- Prompt Acknowledgement after receiving the article

- Thorough Double blinded peer review

- Rapid Publication

- Issue of Publication Certificate

- High visibility of your Published work

Website: https://www.actascientific.com/

Submit Article: https://www.actascientific.com/submission.php Email us: editor@actascientific.com

Contact us: +919182824667 